\title{
ERRATUM
}

\section{Getting to know the public}

Nature Nanotechnology 4, 71 (2009); published online: 6 February 2009; corrected after print: 27 February 2009.

In the version of this editorial originally published, in the second sentence of the last paragraph the word 'referred' should have been 'refereed'. This has been corrected in the HTML and PDF versions. 